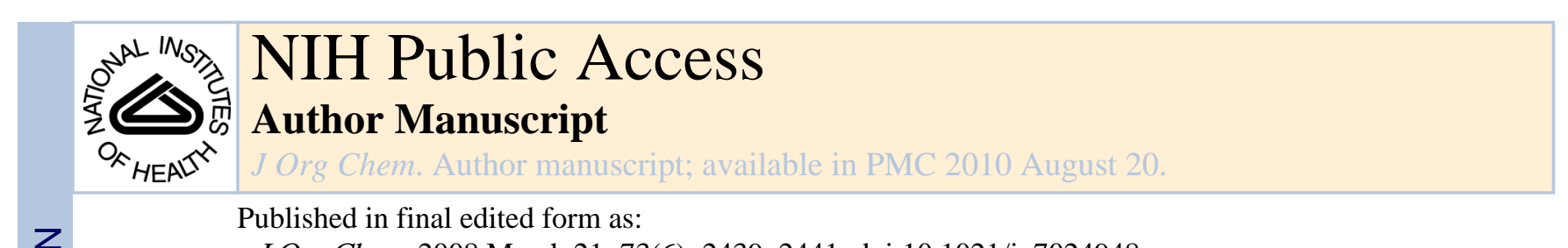

J Org Chem. 2008 March 21; 73(6): 2439-2441. doi:10.1021/jo7024948.

\title{
Gold(I)-Catalyzed Intramolecular Hydroarylation of Allenes
}

\author{
Michael A. TarselliMichel R. Gagné* \\ Caudill Laboratories, University of North Carolina at Chapel Hill, Chapel Hill, North Carolina \\ 27599
}

Abstract

Gold(I) complexes react with 4-allenyl arenes in an exo fashion to furnish vinyl-substituted benzocycles. Phosphite gold(I) monocations were found to be optimal, and the catalyst was tolerant of ethers, esters, and pyrroles. Reactions proceeded in unpurified solvent at room temperature.

The Friedel-Crafts reaction has been a part of many successful transformations in organic chemistry. 1 The reaction has been accelerated by strong acids and by stoichiometric and catalytic quantities of various metals. Recent developments on the topic of catalytic cycloarylation reactions include the gold-(I)-catalyzed arylation of allenes 2,3 by indoles (Widenhoefer4) and pyrroles (Nelson5) and the gold(III)-catalyzed hydroarylation of alkynes reported by He6 (Scheme 1). Hashmi has also shown that intermolecular addition of furans to allenes can be achieved. ${ }^{7}$ The mechanisms are presumed to proceed by an initiating allene activation by the electrophilic gold(I) cation.

Related to these first demonstrations is our recent gold(I)-catalyzed cycloisomerization of 1,6-ene-allenes ${ }^{8}$ (eq 1). The proposed mechanism paralleled the Nelson/Widenhoefer systems with gold(I) acting as an allene activator for intramolecular attack by the alkene to generate an intermediate carbenium ion. Elimination and protodeauration yielded the vinylcyclohexene with variable regiocontrol.

(C) 2008 American Chemical Society

*mgagne@unc.edu.

Supporting Information Available: Experimental procedures, ${ }^{1} \mathrm{H},{ }^{13} \mathrm{C}$, and HRMS data for all new compounds. This material is available free of charge via the Internet at http://pubs.acs.org. 


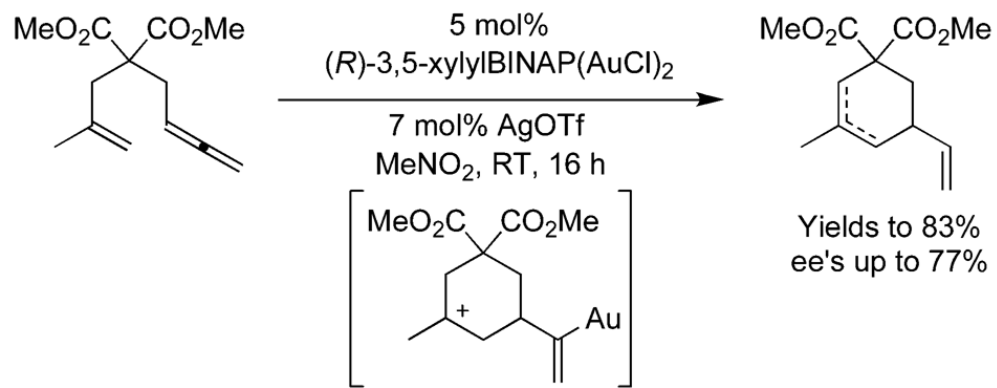

Arenes exhibit a wide range of $\pi$-nucleophilicities as characterized by the Mayr $N$ values, ${ }^{9}$ which quantify and rank their rates of reaction with a common electrophile. Comparing these values to the allene activations reported in the literature revealed a focus on alkene $(N$ $=-1.00$ to 1.20 ) and heteroaromatic (furan/indole/pyrrole; $N=3.60-7.00$ ) nucleophiles (Scheme 2). ${ }^{10}$

Since a number of interesting nucleophiles occupy the spectrum between alkenes and $\mathrm{N}$ heterocycles, we initiated efforts to examine arene-allene cycloisomerizations. One expected benefit was the rearomatization-driven regioselective elimination to products. To develop this concept, we began with the relatively activated dimethoxy substrate 2 and the optimum catalyst for the ene-allene cycloisomerization 3,5-xylyl-BINAP-(AuCl $)_{2} / \mathrm{AgBF}_{4}$. Gratifyingly, the desired vinylated product 3 was obtained, but the rate was slower than desired ( $>16 \mathrm{~h}$ for full conversion).

To improve the reaction rate, a number of alternative catalysts were examined. The best of these was the triphenylphosphite-derived catalyst ${ }^{11} \mathbf{1}$, which was an easily prepared, colorless, crystalline material that was bench stable for several weeks. ${ }^{12}$ The less basic phosphite ligand ${ }^{13}$ generated a catalyst that was significantly more effective (Scheme 3). 14 The reaction produces benzocyclic products that are similar to those reported by Ma15 from Brønsted activation of allylic alcohols and by Cook $^{16}$ utilizing In(III)-mediated atomtransfer cyclization.

As shown in Table 1, dichloromethane in combination with the $\mathrm{SbF}_{6}-$ counterion was optimum with regard to rate and yield of $\mathbf{3}$. Under these conditions, the catalyst load could be reduced to $3 \mathrm{~mol} \%$ with reasonable reaction times and little change in yield.

Utilizing the standard protocol shown in Scheme 3, a variety of arene nucleophiles were examined (Table 2). Generally speaking, the scope was limited to electron-rich arenes but was tolerant of ethers, acetals, and, not surprisingly, a pyrrole. ${ }^{5}$ The naphthalene substrate (Mayr parameter ${ }^{9} N=-3.9$ ) was especially well-behaved. Unfortunately, coordinating aromatics such as triazoles, isoxazoles, and oxazoles were not effective, likely due to nonproductive coordination to the gold(I) catalyst. Substrates for this chemistry were obtained from the benzylation of monoallenylmalonate ${ }^{4 b}$ with base in THF/DMF. ${ }^{17}$

In cases where the arene nucleophile $N$ parameter was sufficiently high, the catalyst loading could be lowered to further increase reaction efficiency (Table 3, entry 7). The catalyst was also tolerant of substitution at the allene terminus and variation of the malonate linker (Scheme 4). 
To ensure that the above transformations were indeed proceeding by gold catalysis, a series of control experiments were carried out. Interestingly, $\mathbf{3}$ was obtained from $\mathbf{2}$ using stoichiometric amounts of silver but only at higher temperature and longer reaction times (Table 3). Catalytic quantities of triflic acid (5 mol \%), $\mathrm{HNTf}_{2}(1 \mathrm{~mol} \%)$, or $\mathrm{HBF}_{4}(1$ and 5 mol \%) did not produce 3, ruling out the possibility of a Brønsted pathway. As expected, leaving out the halide abstraction agent did not provide an active catalyst, reinforcing the notion of a $\mathrm{P}(\mathrm{OPh})_{3} \mathrm{Au}^{+}$active catalyst.

With less activated aryl rings, such as the 4-tert-Bu substrate $\mathbf{2 0}$, a major byproduct was allene hydration to methyl ketone 21 (eq 2). The $N$ value of $\sim-4.0$ for a tert-butylphenyl group likely represents the lower limit for sufficient $\pi$-nucleophilicity to add to the $\mathrm{Au}^{+}$activated allene. More electron-deficient arenes $\left(\mathrm{NO}_{2} \mathrm{Ar}, \mathrm{BrAr}\right.$, IAr, etc.) were cleanly converted to the methyl ketone with no trace of cycloisomerized product. A related transformation was recently reported. ${ }^{18}$

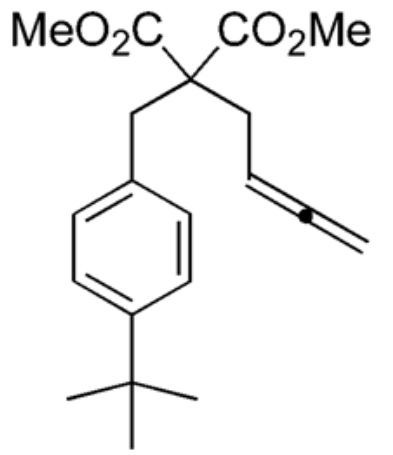

20
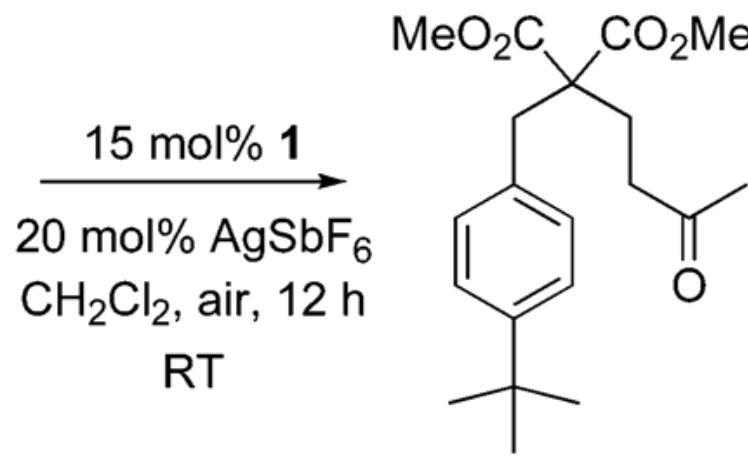

21

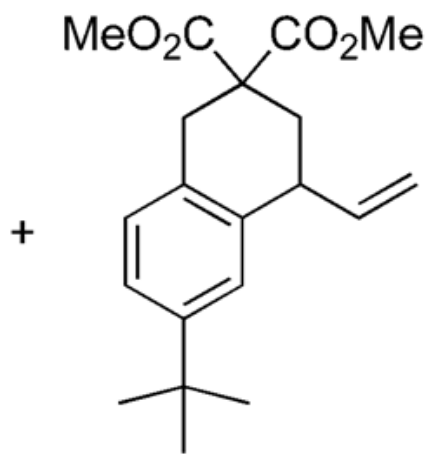

22

\section{$1: 1$ ratio $88 \%$ mass balance recovered}

Attempts to minimize the allene hydration by using anhydrous $\mathrm{CH}_{2} \mathrm{Cl}_{2}$ and adding $4 \AA \mathrm{AMS}$ only led to low conversions ( $<30 \%, 72 \mathrm{~h})$. We speculate that the adventitious water acts as a proton shuttle to modulate the rearomatization and protodeauration steps of the mechanism. 19

In summary, a highly electrophilic phosphite gold(I) catalyst has been applied to the intramolecular allene hydroarylation reaction, producing vinylbenzocycles in good to excellent yields. The catalyst is tolerant of trace water and oxygen, it is bench-stable, and it can be utilized in air with unpurified commercial solvent.

\section{Experimental Section}

\section{Representative Cycloisomerization Procedure}

To a $5 \mathrm{~mL}$ vial charged with a stirbar, 1 (27.2 $\mathrm{mg}, 0.05 \mathrm{mmol}, 1.0$ equiv), and $\mathrm{AgSbF}_{6}$ (24.0 $\mathrm{mg}, 0.07 \mathrm{mmol}, 1.4$ equiv) was added dichloromethane $(1.0 \mathrm{~mL})$ by syringe, at which point a white-gray suspension formed. After $2 \mathrm{~min}, 2$ (168 mg, $0.5 \mathrm{mmol}, 10$ equiv) was added by pipet. The suspension turned deep green within $20 \mathrm{~min}$. After $6 \mathrm{~h}$, the reaction was loaded directly onto a silica flash column and purified with 1:7 ethyl acetate/hexanes. Yield: $85 \%$ of 3 as a clear oil. ${ }^{1} \mathrm{H}$ NMR $\left(400 \mathrm{MHz}, \mathrm{CDCl}_{3}\right): \delta 6.23(\mathrm{~s}, 2 \mathrm{H}), 5.74(\mathrm{~m}, 1 \mathrm{H}), 4.90(\mathrm{~d}, 1 \mathrm{H}, J=$ 
$10.4 \mathrm{~Hz}), 4.68(\mathrm{~d}, 1 \mathrm{H}, J=17.2 \mathrm{~Hz}), 3.77(\mathrm{~s}, 3 \mathrm{H}), 3.70(\mathrm{~s}, 3 \mathrm{H}), 3.66(\mathrm{~s}, 3 \mathrm{H}), 3.64(\mathrm{~s}, 3 \mathrm{H})$, $3.34(\mathrm{~d}, 1 \mathrm{H}, J=16 \mathrm{~Hz}), 2.99(\mathrm{~d}, 1 \mathrm{H}, J=16.4 \mathrm{~Hz}), 2.48(\mathrm{~m}, 1 \mathrm{H}), 2.29(\mathrm{~m}, 1 \mathrm{H}) .{ }^{13} \mathrm{C}(100$ $\mathrm{MHz}): \delta 171.8,171.7,159.1,158.6,141.3,135.8,113.3,104.3,97.1,55.3,55.2,52.6,52.4$, 35.4, 35.0, 34.3. HRMS-ESI+: 357.131 calcd for $\mathrm{C}_{18} \mathrm{H}_{22} \mathrm{O}_{6}+\mathrm{Na}$, found 357.131.

\section{Supplementary Material}

Refer to Web version on PubMed Central for supplementary material.

\section{Acknowledgments}

Support from the National Institute of General Medicine (GM-60578) is greatly appreciated.

\section{References}

(1)(a). Olah, GA. Friedel-Crafts and Related Reactions. Wiley-Interscience; New York: p. 1963-1965. (b) Bandini M, Emer E, Tommasi S, Umani-Ronchi A. Eur. J. Org. Chem 2006:3527-3544.

(2)(a). For recent reviews on gold catalysis, see: Hashmi ASK. Chem. Rev 2007;107:3180-3211. [PubMed: 17580975] (b) Fürstner A, Davies PW. Angew. Chem., Int. Ed 2007;46:3410-3449. (c) Hashmi ASK, Hutchings GJ. Angew. Chem., Int. Ed 2006;45:7896-7936.

(3)(a). For recent examples of gold-catalyzed C-nucleophile additions to allenes, see: Huang X, Zhang L. Org. Lett 2007;9:4627-4630. [PubMed: 17914836] (b) Luzung M, Mauleon P, Toste FD. J. Am. Chem. Soc 2007;129:12402-12403. [PubMed: 17887681] (c) Kim SM, Park JH, Choi SY, Chung YK. Angew. Chem., Int. Ed 2007;46:6172-6175. (d) Linghu X, Kennedy-Smith JJ, Toste FD. Angew. Chem., Int. Ed 2007;46:7671-7673.

(4)(a). Liu C, Widenhoefer RA. Org. Lett 2007;9:1935-1938. [PubMed: 17428061] (b) Zhang Z, Liu C, Kinder RE, Han X, Qian H, Widenhoefer RA. J. Am. Chem. Soc 2006;128:9066-9073. [PubMed: 16834380]

(5). Liu Z, Wasmuth A, Nelson SG. J. Am. Chem. Soc 2006;128:10352-10353. [PubMed: 16895385]

(6). Shi Z, He C. J. Org. Chem 2004;69:3669-3671. [PubMed: 15152995]

(7). Hashmi ASK, Schwarz L, Choi J-H, Frost TM. Angew. Chem., Int. Ed 2000;39:2285-2288.

(8). Tarselli MA, Chianese AR, Lee SJ, Gagné MR. Angew. Chem., Int. Ed 2007;46:6670-6673.

(9). Mayr H, Kempf B, Ofial AR. Acc. Chem. Res 2003;36:66-77. [PubMed: 12534306]

(10). As this manuscript was being completed, Fujii and Ohno reported a $\left(\mathrm{PR}_{3}\right) \mathrm{Au}(\mathrm{OTf})$ catalyzed, endo-selective hydroarylation of allenes (Wa-tanabe T, Oishi S, Fujii N, Ohno H. Org. Lett 2007;9:4821-4824. [PubMed: 17924641]

(11). Schneider D, Schier A, Schmidbaur H. J. Chem. Soc., Dalton Trans 2004:1995-2005.

(12). The catalyst can be recrystallized from $\mathrm{CH}_{2} \mathrm{Cl}_{2}$ /hexanes in a vapor chamber and exhibits a gradual darkening over the course of 1 month.

(13). Tolman CA. Chem. Rev 1977;77:313-348.

(14). A phosphite-Au(I) catalyst for alkyne activation has recently appeared; see: Nieto-Oberhuber C, Pérez-Galán P, Herrero-Gómez E, Lauterbach T, Rodríguez C, López S, Bour C, Rosellón A, Cárdenas DJ, Echavarren AM. J. Am. Chem. Soc 2008;130:269-279. [PubMed: 18076170]

(15)(a). Ma S, Zhang J. Tetrahedron Lett 2002;43:3435-3438. (b) Ma S, Zhang J. Tetrahedron 2003;59:6273-6283.

(16). Hayashi R, Cook GR. Org. Lett 2007;9:1311-1314. [PubMed: 17346056]

(17). Makino T, Itoh K. J. Org. Chem 2004;69:395-405. [PubMed: 14725453]

(18). Hydration of allenyl acetates under solvolysis conditions has been observed: Alameda-Angulo C, Quiclet-Sire B, Zard SZ. Tetrahedron Lett 2006;47:913-916.

(19). The Ohno conditions reported in ref 10 include $10 \%$ acetic acid to modulate this step; their reported rates are higher than the present results. In a single experiment, we have shown that $\mathbf{2}$ is converted to 3 (as a mixture of alkene isomers) by $3 \mathrm{~mol} \%$ of $\mathbf{1} / 5 \mathrm{~mol}_{\%}$ of $\mathrm{AgSbF}_{6}$ in 10:1 $\mathrm{DCM} / \mathrm{AcOH}$ in $<1 \mathrm{~h}$. 

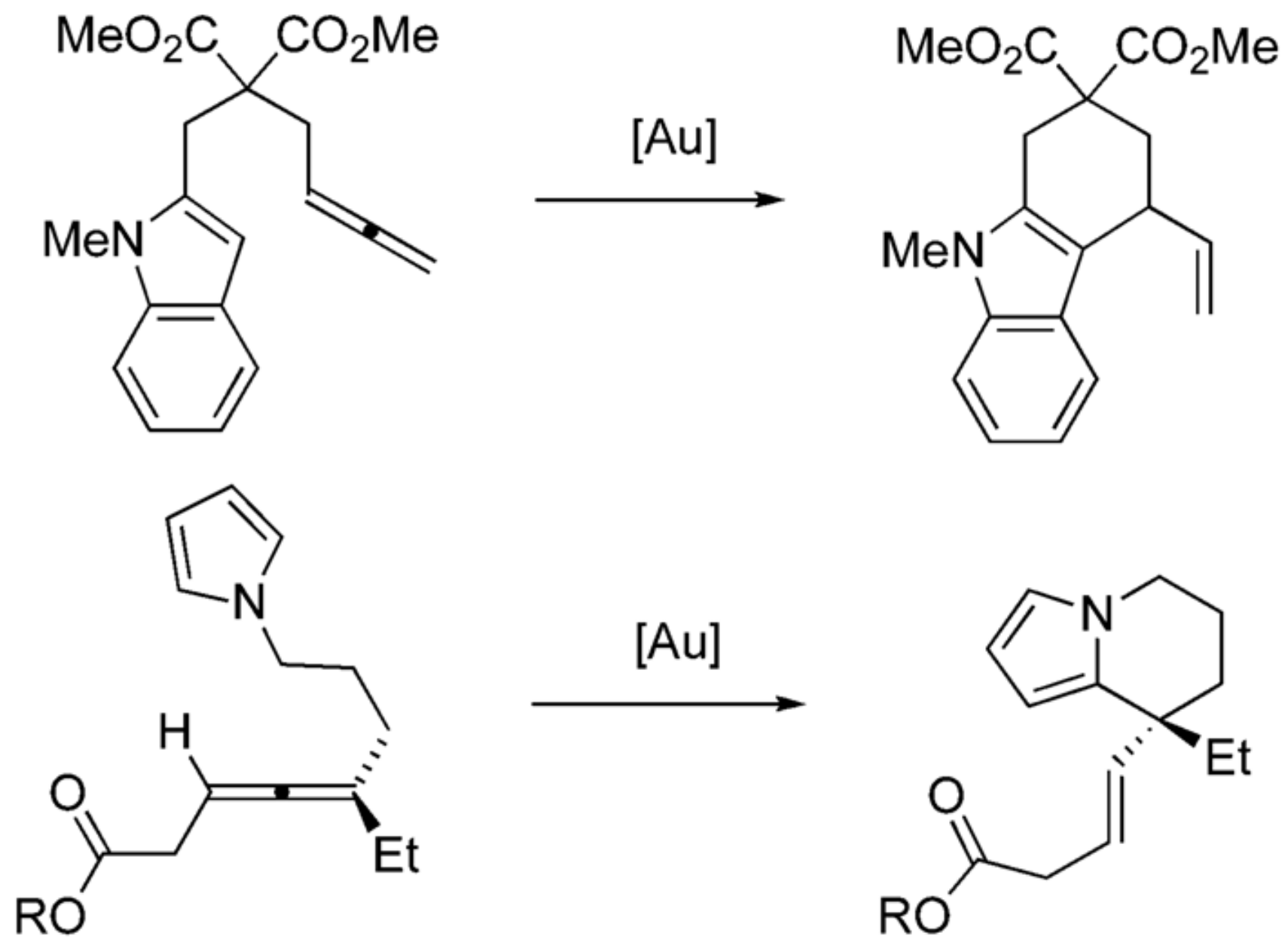

Scheme 1.

Recent Gold(I)-Catalyzed Allene Arylations ${ }^{4,5}$ 

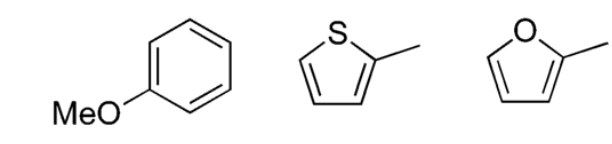<smiles>Cn1ccc2ccccc21</smiles><smiles>c1ccccc1</smiles>

$-1.2+1.3$

$+3.6$<smiles>[13CH3]</smiles><smiles>C1CCNCC1</smiles><smiles>[131I-]</smiles><smiles>C=C(C)C</smiles><smiles>COc1cccc(OC)c1</smiles><smiles>Cn1cccc1</smiles><smiles>C1CCCCC1</smiles><smiles>COC1=CC[18O]C1</smiles>
$+1.1$ $+2.5$ $+5.9$

increasing nucleophilicity

Scheme 2.

Representative $N$ Values $^{8}$ for $\pi$-Nucleophiles 


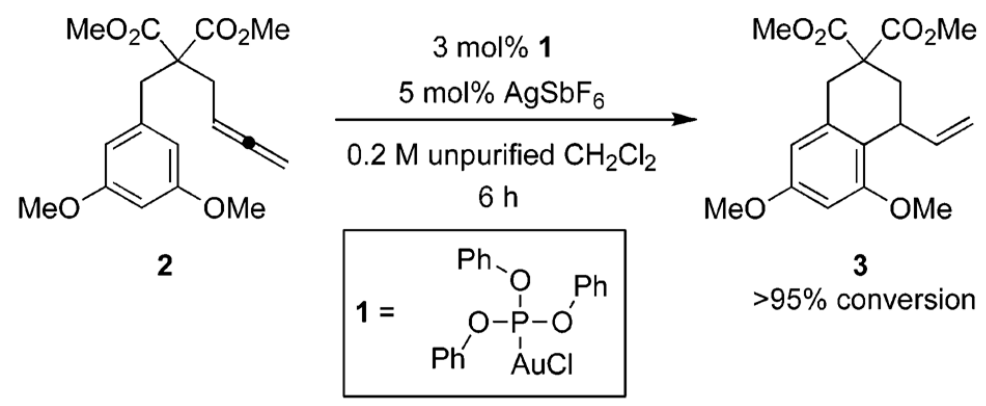

Scheme 3.

Optimized Conditions with Activated Substrate 2 
<smiles>COC(=O)C(CC=C=C(C)C)(Cc1cc(OC)cc(OC)c1)C(=O)OC</smiles>

16<smiles>C=C=CCC(COC)(COC)Cc1cc(OC)cc(OC)c1</smiles>

18

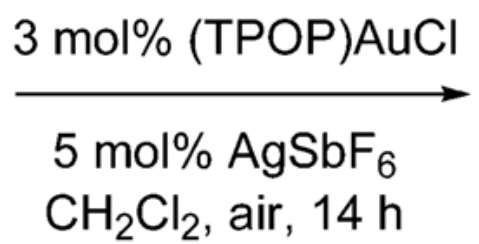
$64 \%$

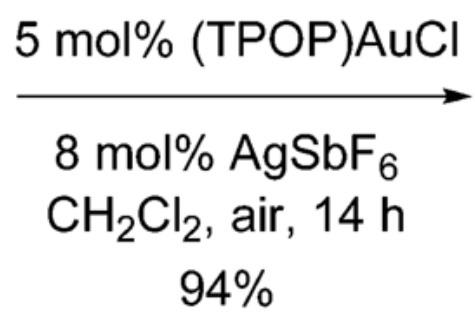
$94 \%$

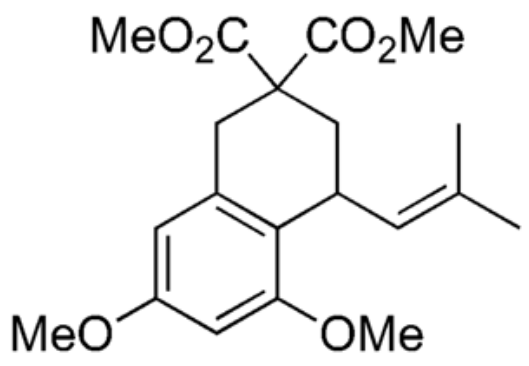

17<smiles>C=CC1CC(COC)(COC)Cc2cc(OC)cc(OC)c21</smiles>

19

Scheme 4.

Variation in Linker/Allene Substitution 
Table 1

Optimization of Solvent and Silver Counterion for the Conversion of 2 to 3 (Scheme 3) ${ }^{a}$

\begin{tabular}{|c|c|c|c|}
\hline entry & solvent $b$ & $\mathbf{X}^{-}$ & conversion $^{c}\left(\begin{array}{ll}\% & 3\end{array}\right)^{d}$ \\
\hline 1 & $\mathrm{CH}_{2} \mathrm{Cl}_{2}$ & OTf & 92 \\
\hline 2 & toluene & OTf & 52 \\
\hline 3 & hexane & OTf & 73 \\
\hline 4 & $\mathrm{Et}_{2} \mathrm{O}$ & OTf & 20 \\
\hline 5 & THF & OTf & 36 \\
\hline 6 & $\mathrm{MeNO}_{2}$ & OTf & 55 \\
\hline 7 & $\mathrm{CH}_{2} \mathrm{Cl}_{2}$ & $\mathrm{BF}_{4}$ & $100(75)$ \\
\hline 8 & $\mathrm{CH}_{2} \mathrm{Cl}_{2}$ & $\mathrm{NTf}_{2}$ & $79(80)$ \\
\hline 9 & $\mathrm{CH}_{2} \mathrm{Cl}_{2}$ & $\mathrm{PF}_{6}$ & $35(72)$ \\
\hline 10 & $\mathrm{CH}_{2} \mathrm{Cl}_{2}$ & $\mathrm{SbF}_{6}$ & $89(\mathbf{8 8})$ \\
\hline 11 & $\mathrm{CH}_{2} \mathrm{Cl}_{2}$ & OTs & $51(58)$ \\
\hline 12 & $\mathrm{CH}_{2} \mathrm{Cl}_{2}$ & $\mathrm{ClO}_{4}$ & $92(76)$ \\
\hline \multicolumn{4}{|c|}{ Reaction conditions: $5 \mathrm{~mol} \%$ of $\mathbf{1}, 7 \mathrm{~mol} \%$ of $\mathrm{AgX}, 0.2 \mathrm{M}$ in $\mathbf{2}$ at rt. } \\
\hline \multicolumn{4}{|c|}{ 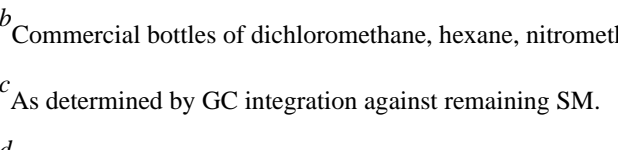 } \\
\hline
\end{tabular}




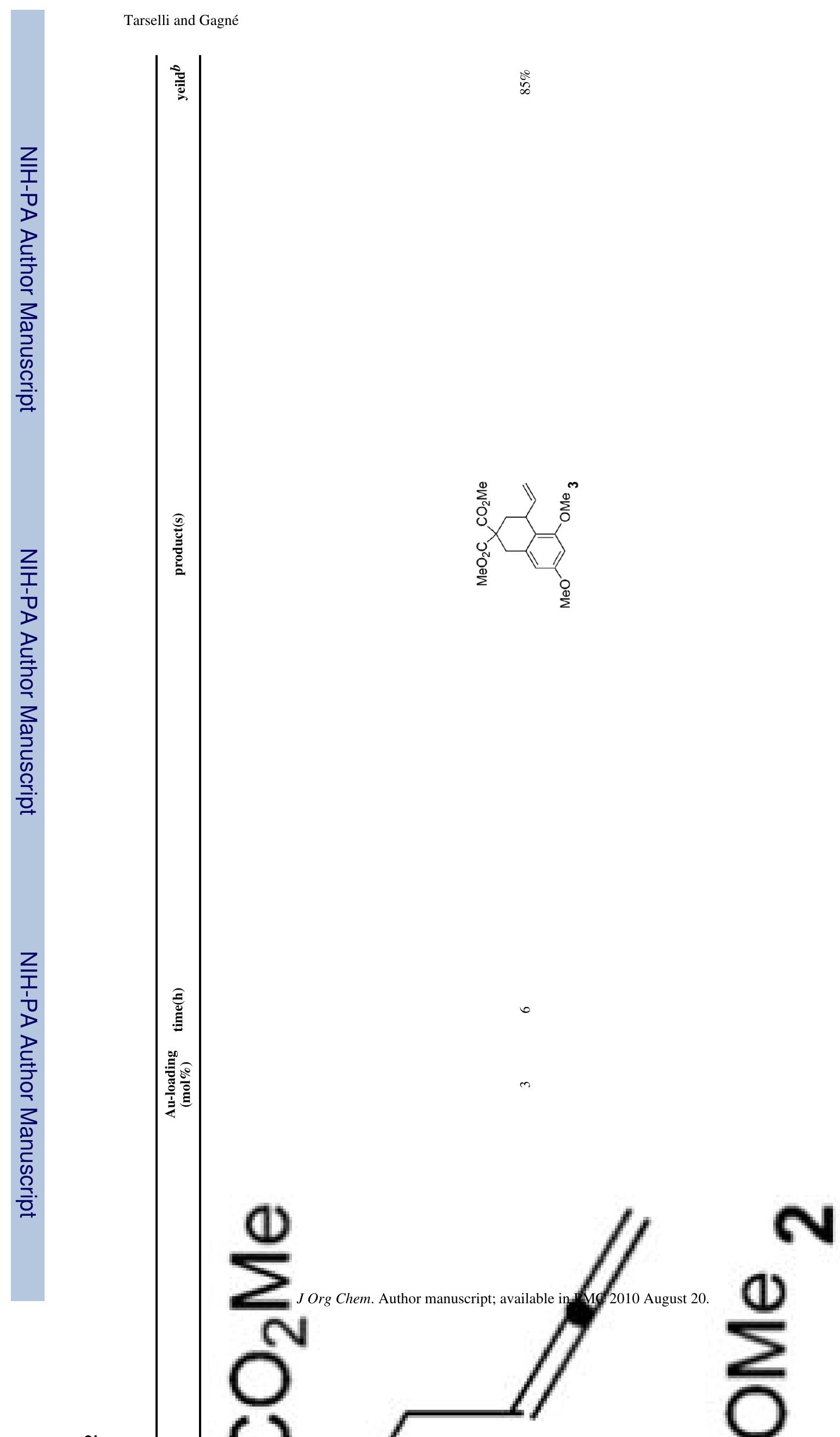




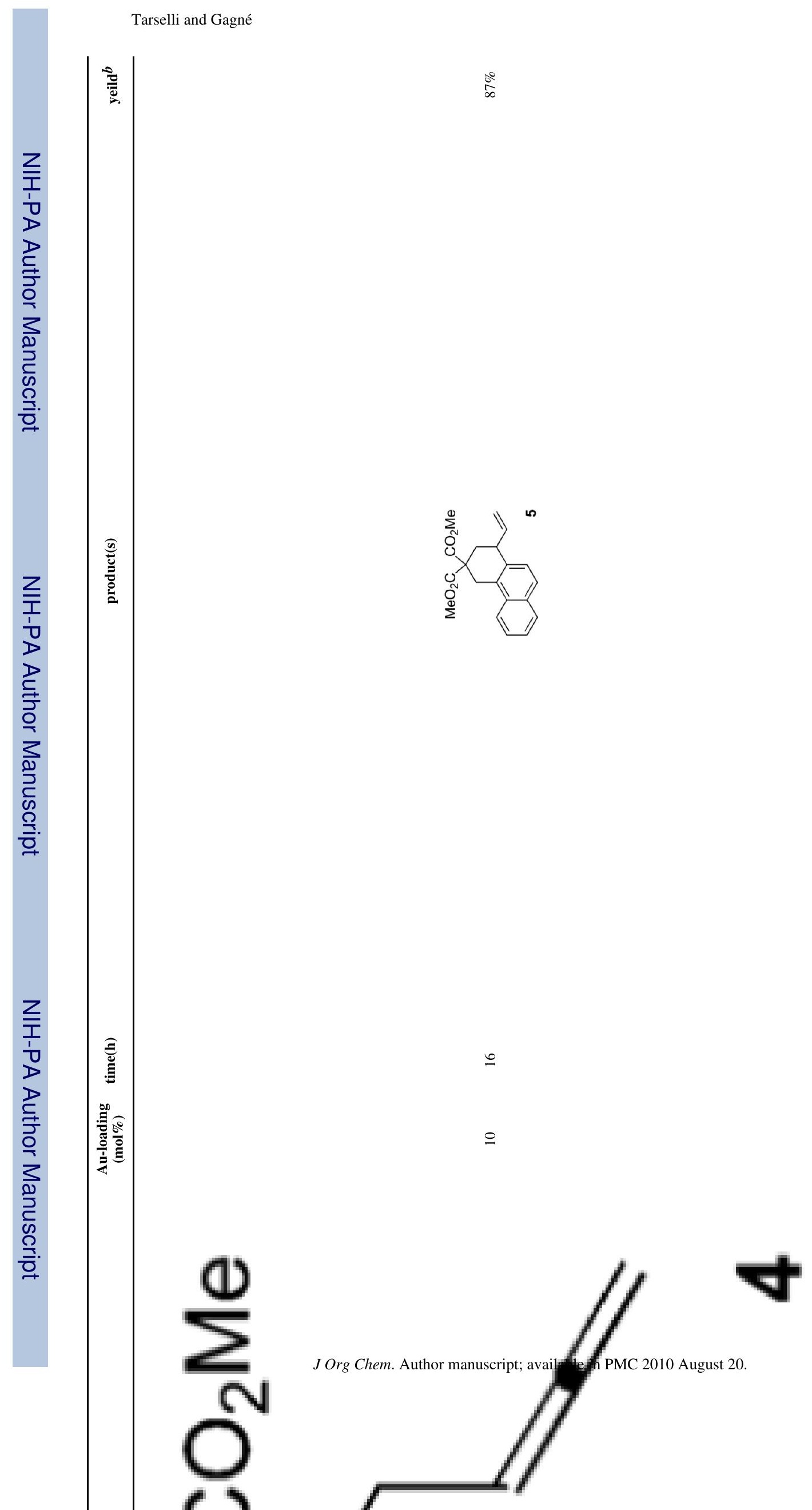




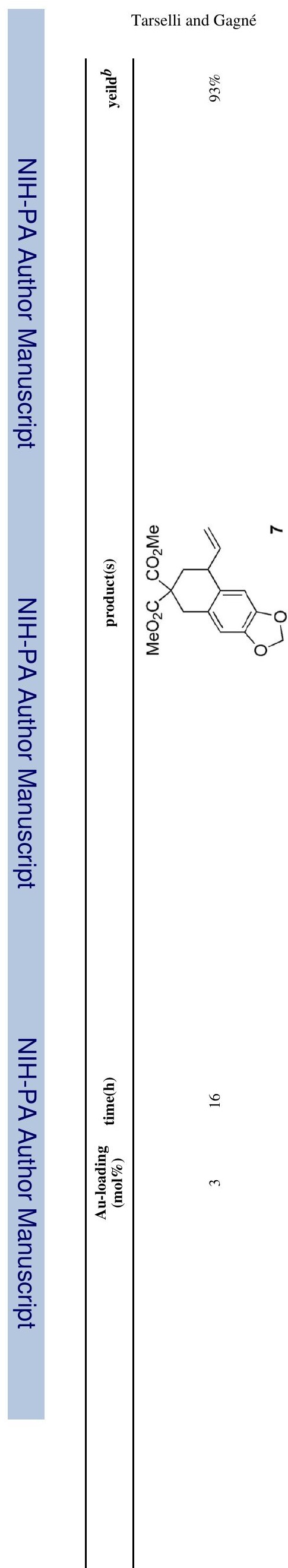

Page 12 


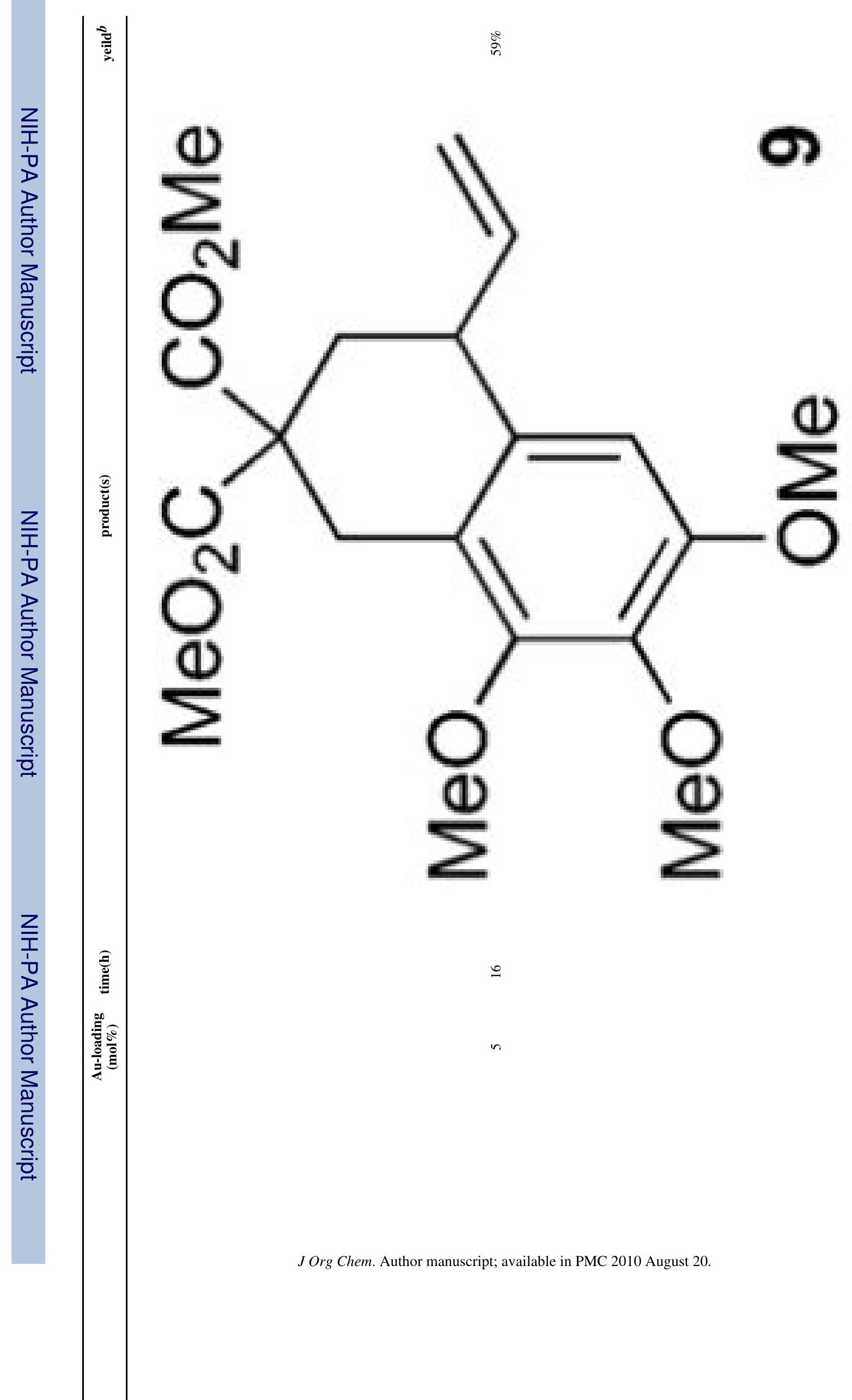




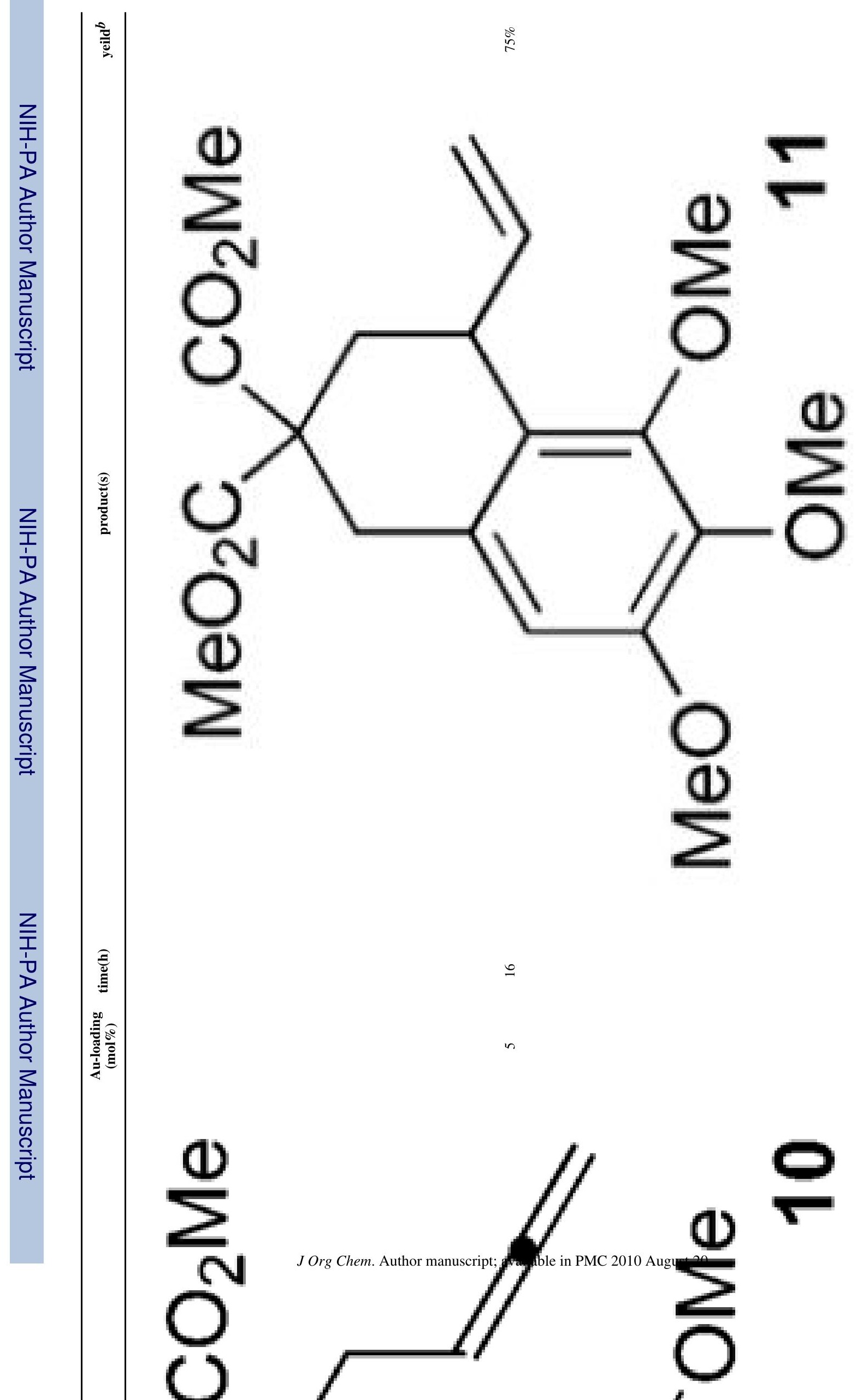




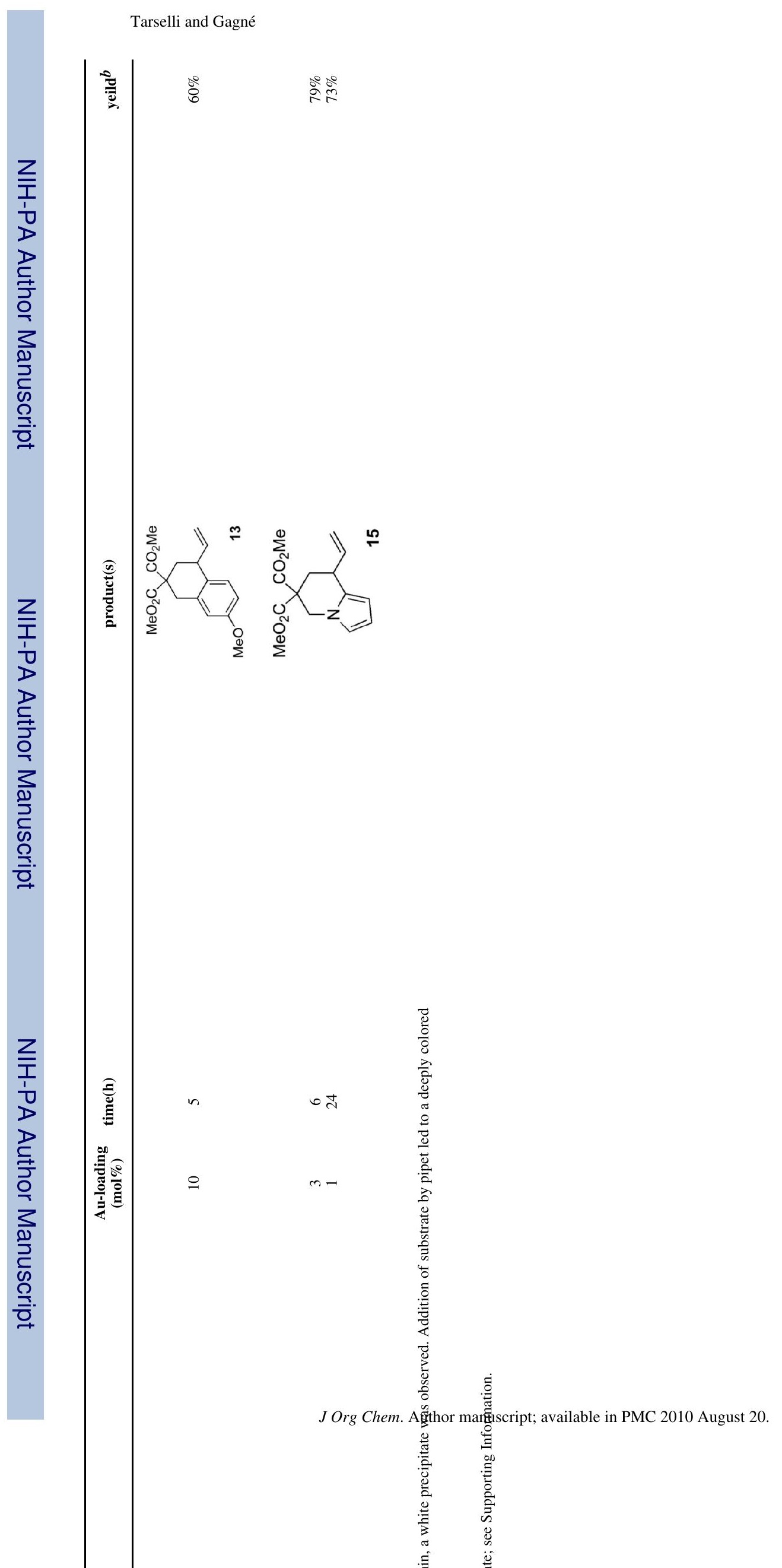

Page 15 
Table 3

Control Experiments ${ }^{a}$ Using 2 to Test for $\mathrm{Ag}^{+}$or $\mathrm{H}^{+}$Background Catalysis

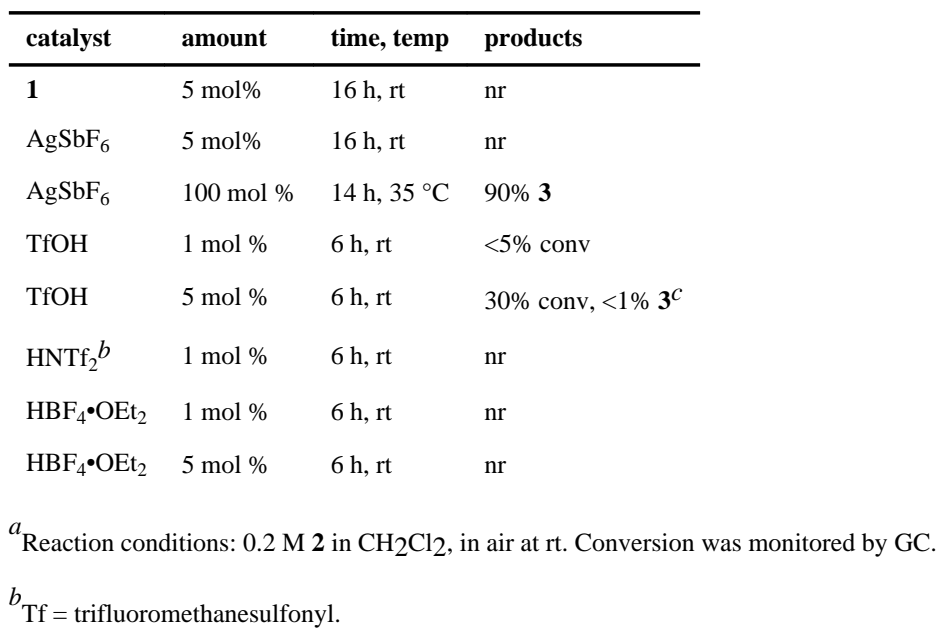

${ }^{c}$ Six products were observed by GC-MS, the predominant $(\sim 30 \%)$ being allene hydrolysis to the methyl ketone $(\mathrm{m} / \mathrm{z}=352)$. 